\title{
The Therapeutic Targets of miRNA in Hepatic Cancer Stem Cells
}

\author{
Sabrina Bimonte, ${ }^{1}$ Maddalena Leongito, ${ }^{1}$ Antonio Barbieri, ${ }^{2}$ Vitale del Vecchio, ${ }^{2}$ \\ Michela Falco, ${ }^{2}$ Aldo Giudice, ${ }^{3}$ Raffaele Palaia, ${ }^{1}$ Vittorio Albino, ${ }^{1}$ Raimondo Di Giacomo, ${ }^{1}$ \\ Antonella Petrillo, ${ }^{4}$ Vincenza Granata, ${ }^{4}$ and Francesco Izzo $^{1}$ \\ ${ }^{1}$ Division of Abdominal Surgical Oncology, Hepatobiliary Unit, National Cancer Institute “G. Pascale Foundation” IRCCS, \\ 80131 Naples, Italy \\ ${ }^{2}$ Animal Facility Unit, National Cancer Institute of Naples “G. Pascale Foundation” IRCCS, 80131 Naples, Italy \\ ${ }^{3}$ Epidemiology Unit, National Cancer Institute of Naples "G. Pascale Foundation" IRCCS, 80131 Naples, Italy \\ ${ }^{4}$ Division of Radiology, National Cancer Institute "G. Pascale Foundation” IRCCS, 80131 Naples, Italy
}

Correspondence should be addressed to Sabrina Bimonte; s.bimonte@istitutotumori.na.it

Received 18 November 2015; Revised 23 February 2016; Accepted 14 March 2016

Academic Editor: Qiang Wu

Copyright (C) 2016 Sabrina Bimonte et al. This is an open access article distributed under the Creative Commons Attribution License, which permits unrestricted use, distribution, and reproduction in any medium, provided the original work is properly cited.

\begin{abstract}
Hepatocellular carcinoma (HCC) is the fifth most common cancer worldwide malignancy and the third leading cause of cancer death in patients. Several studies demonstrated that hepatic cancer stem cells (HCSCs), also called tumor-initiating cells, are involved in regulation of HCC initiation, tumor progression, metastasis development, and drug resistance. Despite the extensive research, the underlying mechanisms by which HCSCs are regulated remain still unclear. MicroRNAs (miRNAs) are able to regulate a lot of biological processes such as self-renewal and pluripotency of HCSCs, representing a new promising strategy for treatment of HCC chemotherapy-resistant tumors. In this review, we synthesize the latest findings on therapeutic regulation of HCSCs by miRNAs, in order to highlight the perspective of novel miRNA-based anticancer therapies for HCC treatment.
\end{abstract}

\section{Introduction}

Hepatocellular carcinoma (HCC) is the fifth most common cancer in the world and in most cases it develops in patients with chronic liver diseases such as viral infections and cirrhosis. Treatment for primary liver cancer depends on the location and stage of the cancer and liver's functionality; however, in many cases HCC is diagnosed in patients with an advanced stage. Thus, it is difficult to treat patients at surgical and pharmacological levels [1]. Treatment options include surgical resection, thermal ablation, systemic chemotherapy, transarterial chemoembolization, and selective internal radiation therapy with poor prognosis in all approaches due to the high recurrence rate and to the tumor chemoresistance.

The emerging cancer stem cell (CSC) theory based on targeting of CSCs [2] suggests new alternative therapeutic approaches to treat various types of tumors that could overcome defeats of the traditional therapy. Thanks to the identification of the major signaling pathways, transcriptional factors, surface markers, microRNA (miRNAs), and other factors that confer stem-like properties to CSCs, various therapeutic implications have been developed until now.

Hepatic cancer stem cells (HCSCs) represent a subpopulation of cells positive for different markers including CD133, CD90, and EpCAM [3]. These cells are responsible of the tumor initiation and progression and are also involved in the metastasis processes and chemoresistance. Thanks to the HCSCs characterization, it is possible to study the impact of any molecular mediators highly expressed in HCSCs during carcinogenesis, through the identification of specific stemness markers. The major stem-maintenance pathways involved in HCSCs regulation are TGF- $\beta$ family, Wnt $\beta$ catenin axis, PI3K/AKT/mTOR, and EpCAM.

It is of note that these signaling pathways are subjected to different homeostasis system and in particular are regulated epigenetically by miRNAs. MiRNAs, by acting as oncogenes 
or oncosuppressors, are able to regulate many biological processes such as self-renewal and pluripotency of HCSCs $[4,5]$, representing a new promising strategy for treatment of chemotherapy-resistant HCC tumors.

In this review, we summarized the latest findings on the therapeutic regulation of HCSCs induced by miRNA and we try to elucidate the underlying mechanisms in order to highlight the perspective of novel miRNA-based anticancer therapies for HCC treatment.

\section{Hepatic Cancer Stem Cells: Biogenesis and Functions}

Cancer stem cells (CSCs) or tumor-initiating cells (T-ICs) are tumor cells discovered in solid and hematological tumors. These cells share stem-like properties and are involved in the tumorigenesis, in development of metastases, and in selfrenewal processes. Bonnet and Dick described CSCs for the first time, in acute myeloid leukemia [6]. Several studies showed their existence in other different types of cancer such as glioma [7], breast [8], colon [9], ovarian [10,11], pancreatic $[12]$, prostate $[13,14]$, lung [15], liver [16], and stomach [17] cancer.

It has been demonstrated that CSCs play important roles in the tumor initiation and maintenance but also in metastasis and cancer relapse induced by the chemoresistance to the conventional therapies [2]. CSCs can be originated by different processes ranging from the transformation of normal stem cells or progenitor cells through multiple gene mutations [18] or by adult progenitor cells and progressive acquisition of stem cell properties through reversal of ontogeny [19] as the epithelial-to-mesenchymal transition (EMT) process. EMT is a biologic process that induces the transformation of a polarized epithelial cell into a mesenchymal cell type with stem-like properties [20]. In addition, it can also confer to the CSCs the ability to generate metastasis, which is uncommon in other cancer cell types. EMT together with reverse transition from mesenchymal to an epithelial phenotype (MET) are involved in embryonic development, which leads to the disruption of epithelial cell homeostasis and the acquisition of a migratory mesenchymal phenotype [21]. The EMT process is controlled by the canonical pathways such as Wnt and transforming growth factor- $\beta$ (TGF- $\beta$ ) [22]. These observations suggest a new concept of migration process based on the existence of two forms of cancer stem cells: (1) stationary cancer stem cells (SCS) and (2) mobile cancer stem cells (MCS). SCSs are involved in tumor initiation and are detectable in the differentiated central area of tumor, while MCSs are known as cells derived from SCSs through the acquisition of EMT.

Hepatic CSCs (HCSCs) have been isolated from heterogeneous tumor tissues, based on the specific surface markers and functional properties. It is of note that various markers have been identified for hepatic cancer stem cells, including CD133, CD90, and EpCAM [3].

The principal HCSCs molecular markers are summarized in Table 1.

\section{Signaling Pathways Involved in the Regulation of HCSCs}

HCSCs show specific features of pluripotency and selfrenewal; this phenotype is strictly regulated by different types of molecular effectors involved in many pathways. Here, we review the latest findings on the most important mediators involved in HCSCs regulation.

3.1. TGF- $\beta$. TGF- $\beta$ is a pleiotropic cytokine involved in embryonic development and adult homeostasis maintenance. It regulates the progression of many human diseases as embryo-defects, autoimmune illness, and cancer progression [57-59]. It has been also demonstrated that TGF- $\beta$ regulates HCSCs cell proliferation and differentiation. Its deregulation induces aberrant expression of IL- 6 resulting in changed differentiation pattern and tumorigenesis [60]. TGF- $\beta$ binds to the heterodimeric surface receptor T $\beta$ RI/T $\beta$ RII. Subsequently, the subunit $\mathrm{T} \beta \mathrm{R}$ is activated by the phosphorylation of the C-term motif Ser-X-Ser of R-Smads or Smad2/3. The result is the formation of oligomeric Smad complex (together with Co-Smad and Smad4) that is then accumulated in the nucleus and regulates gene expression [61, 62]. Other studies showed the interaction between TGF- $\beta$ and other cell effectors signal transducer such as MAPKs, ERK, JNK and p38, PI3K/AKT axis, RhoA GTPase, and PAK2 [63, 64]. Interesting data showed that Smad7 highly expressed in hepatocarcinoma and other types of cancer disease [65] negatively regulates TGF- $\beta$ through $\mathrm{T} \beta \mathrm{RI}$ subunit $[66,67]$ or by interference with the R-Smad-Smad4-DNA complex formation [68]. TGF- $\beta$ signaling also induces endothelial-tomesenchymal transition (EMT) in neoplastic cells.

Emerging evidences indicate that Smad7 also regulates Wnt/ $\beta$-catenin, NF- $\kappa \mathrm{B}$, interleukin-1/Toll-like receptor, and EGF/MAPK signaling pathways $[65,66]$. Recently it has been demonstrated that HCCs with impaired levels of transcription-3/OCT4 have dysfunctional TGF- $\beta$ signaling and share similar properties of cancer progenitor cells [67].

3.2. Wnt/ $\beta$-Catenin. One of the most recurrent pathways involved in HCSCs regulation is the $\mathrm{Wnt} / \beta$-catenin signaling. This signaling regulates development, growth, survival, regeneration, and self-renewal processes in HCC [68]. $\beta$ catenin acts as a pivotal mediator in Wnt/ $\beta$-catenin signaling pathway through the interaction between Frizzled, the receptor of $\mathrm{Wnt}$, and coreceptor lipoprotein receptor related 5/6 (LRP5/6). This event results in the activation of Disheveled (Dvl), in the dissociation of tetrameric $\beta$ catenin/Axin/GSK3 $\beta$ /APC complex, in the reduction of $\beta$ catenin phosphorylation, and in the migration of active $\beta$ catenin to the nucleus (Figure 1).

It has been showed that cytoplastmatic and nuclear accumulation of $\beta$-catenin were founded in $20-40 \%$ of HCC patients, although its target genes were unaffected.

Nuclear $\beta$-catenin interacts with T-cell factor (TCF)/ lymphocyte enhancer factor 1 (LEF1) and some other coactivator as BCL9, Pygo, or CREB-bp to regulate gene transcription of specific sequences $[69,70]$. The prominent targets 
TABLE 1: Cell surface marker of hepatic cancer stem cells.

\begin{tabular}{|c|c|c|c|c|}
\hline Marker & Localization & Structure & Role in cancer & Ref. \\
\hline $\begin{array}{l}\text { CD133 } \\
\text { (prominin 1) }\end{array}$ & Adult stem cells & $\begin{array}{l}\text { Pentaspan transmembrane } \\
\text { glycoprotein }\end{array}$ & $\begin{array}{l}\text { Self-renewal, tumorigenicity, } \\
\text { chemoresistance, and invasiveness }\end{array}$ & {$[23,24]$} \\
\hline $\begin{array}{l}\text { CD90 } \\
(\text { Thy-1) }\end{array}$ & Adult stem cells & $\begin{array}{l}\text { Glycosyl-PI-anchored } \\
\text { glycoprotein }\end{array}$ & $\begin{array}{l}\text { Tumor formation, self-renewal, and } \\
\text { metastasis }\end{array}$ & {$[25]$} \\
\hline $\mathrm{CD} 44$ & Mammalian cell types & Cell surface-glycoprotein & $\begin{array}{l}\text { Tumor formation, chemoresistance, and } \\
\text { metastatic ability }\end{array}$ & {$[26]$} \\
\hline $\mathrm{CD} 13$ & $\begin{array}{l}\text { Predominantly on cells in } \\
\qquad \mathrm{G}_{1} / \mathrm{G}_{0} \text { phase }\end{array}$ & $\begin{array}{l}\mathrm{Zn}^{2+} \text { dep. Membrane bound } \\
\text { ectopeptidase }\end{array}$ & $\begin{array}{l}\text { Tumorigenicity, cell proliferation, } \\
\text { self-renewal, and chemoresistance }\end{array}$ & {$[27]$} \\
\hline $\begin{array}{l}\text { CD24 } \\
\text { (HAS) }\end{array}$ & Differentiating cells & Cell adhesion glycoprotein & $\begin{array}{l}\text { Self-renewal, tumor formation, metastasis, } \\
\text { and chemoresistance }\end{array}$ & [28] \\
\hline OV6 & Oval cells in fetal liver & Surface antigen & Tumor formation and chemoresistance & {$[29]$} \\
\hline DLK1 & $\begin{array}{l}\text { Stem/progenitor hepatic and } \\
\text { fetal liver cells }\end{array}$ & 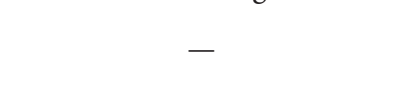 & $\begin{array}{l}\text { Proliferation, self-renewal, tumor formation, } \\
\text { and tumor growth }\end{array}$ & {$[30]$} \\
\hline EpCAM & Progenitors and stem cells & Transmembrane glycoprotein & $\begin{array}{l}\text { Invasiveness, self-renewal, and tumor } \\
\text { formation }\end{array}$ & {$[31]$} \\
\hline GEP & Fetal liver & Hepatic oncofetal protein & Tumorigenicity and chemoresistance & {$[32]$} \\
\hline $\begin{array}{l}\text { SP } \\
\text { (side population) }\end{array}$ & $\begin{array}{l}\text { Cell subpopulation efflux } \\
\text { chemotherapy drugs through } \\
\text { ABC transporters }\end{array}$ & - & $\begin{array}{l}\text { Tumorigenicity, self-renewal, and } \\
\text { chemoresistance }\end{array}$ & {$[33]$} \\
\hline
\end{tabular}

of this signaling are CD44 [71], cyclin D1 [72], and c-myc [73]. c-Myc is considered the preferred target of EpCAM, an adhesion transmembrane glycoprotein, identified as a good marker of HCSCs [74] but also a prognosis biomarker, due to its correlation with more aggressive diseases $[75,76]$.

These data suggest that Wnt signaling is involved in HCSCs maintenance.

3.3. EрCAM. The EpCAM signaling starts with a sequential cleavage of the surface protein, operated by TNF- $\alpha$ converting enzyme (TACE/ADAM17) and a gamma-secretase complex containing presenilin-2 (PS-2) (Figure 1). It results in the separation of the extracellular domain, EpEX, and the cytoplasm releasing of EpICD domain that becomes part of multiprotein complex composed of $\beta$-catenin and LEF (both components present in Wnt/ $\beta$-catenin signaling). A key role in EpCAM pathway is played by FHL2 that first regulates the localization of the cleavage and then acts as a link between EpICD and specific DNA sequences [77]. Some transcriptional factors involved in pluripotent stem cells maintenance, as Nanog, Klf, Sox2, and OCT4, have been described as direct target of EpCAM in human embryonic stem cells [78]. It has been demonstrated that EpCAM is a Wnt-beta-catenin signaling target gene and may be used to facilitate HCC prognosis [79].

3.4. PI3K/AKT/mTOR. The PI3K/AKT/mTOR signaling that has been found to be deregulated in $40-50 \%$ of HCC cases, with less differentiated tumors and with reduction of free disease survival [80].

Specifically, the activation of IRS1, an intracellular mediator of insulin signaling, induces the activation of PI3K (Phosphatidylinositol 3-Kinase). This leads to the phosphorylation of PKB (protein kinase B)/AKT mediated by PDK1 (Pyruvate
Dehydrogenase Kinase Isozyme 1), a positive regulator of the tuberous sclerosis (TSC1-TSC2) complex; the latter promotes the activation of $\mathrm{mTORC1}$, a mammalian target of rapamycin complex 1, through the small GTPase Rheb (Ras homolog enriched in brain). mTORC1 can target and activate S6K1 (ribosomal protein S6 kinase) and 4E-BP1 (eukaryotic initiation factor $4 \mathrm{E}$ binding protein 1 ), major regulators of protein translation. The Phosphatase PTEN (Phosphatase and tensin homolog) physiologically inhibits the downstream activity of $\mathrm{PI} 3 \mathrm{~K} / \mathrm{AKT}$ axis and is frequently deregulated in HCC (66\% of tumor incidence in PTEN-deficient mice) [81]; moreover, it is correlated with poor prognosis and more frequent metastasis [82].

3.5. Hedgehog. Hedgehog pathway plays an important role during embryonic development and in cell fate maintenance. It is activated by binding of ligands (Desert, Indian, and Sonic Hedgehog) to the membrane based patched (Ptc) receptors [83, 84] (Figure 1). Recent reports established the role of Hedgehog signaling in HCC [85-87].

Figure 1 shows a summarized view of pathways involved in regulation of HCSCs.

\section{Therapeutic Targets of miRNA in Hepatic Cancer Stem Cells}

Recent studies showed the role of miRNA in many biological processes, including the regulation of carcinogenesis, sharing both oncogenes and oncosuppressor functions [36, 54, 8890]. The deregulation of miRNA expression levels represents an important feature of tumor cells, resulting into an aberrant epigenetic regulation. Regarding liver tumor progression, miRNAs act as tumor suppressors (miR-122, miR26, and miR223 ) or as oncogenic miRNAs (miR-130b, miR-221, and miR222). 


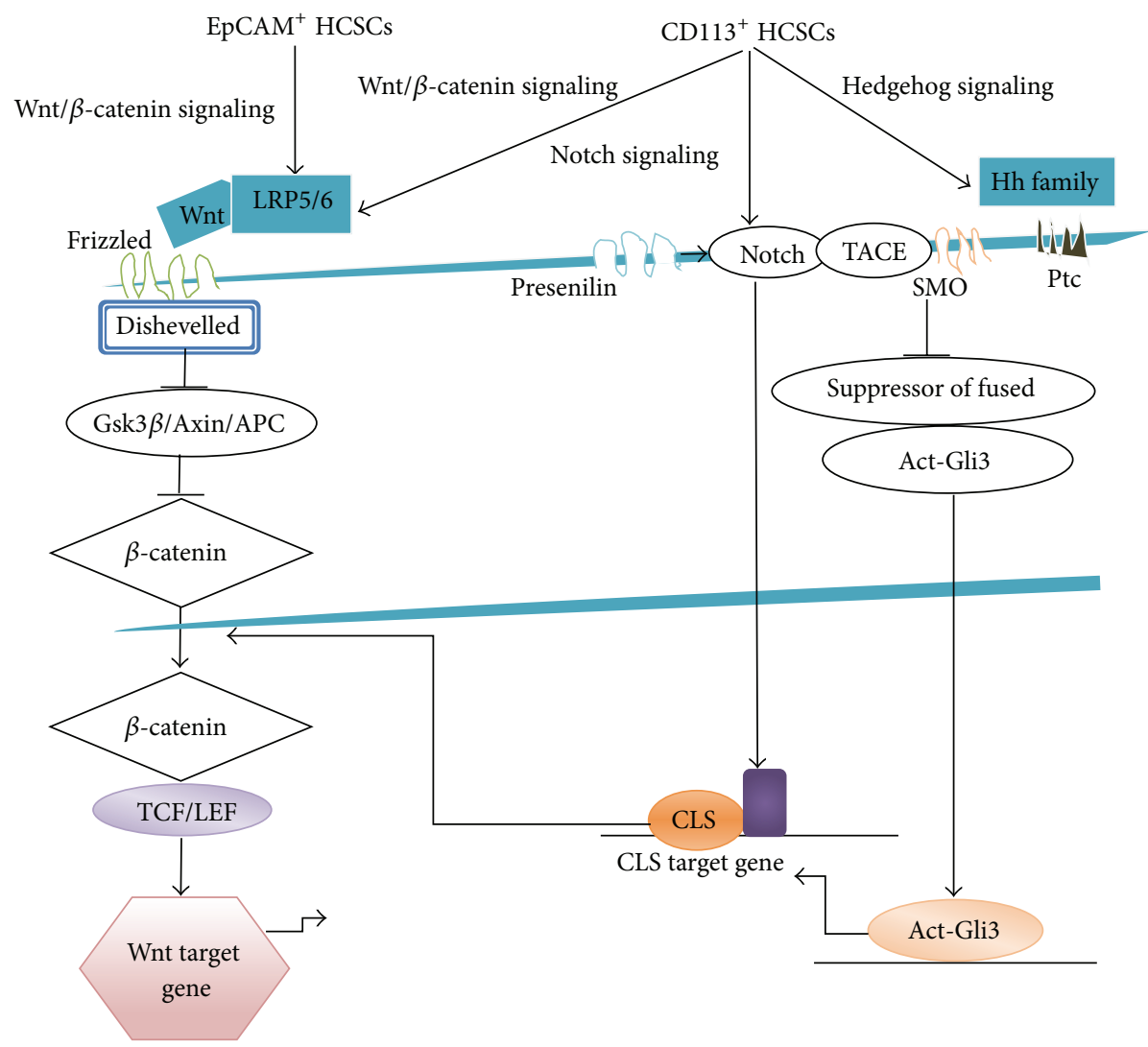

FIGURE 1: Key signaling pathways that regulate the function of hepatic cancer stem cells. The cartoon recapitulates the principle signaling pathways that regulate the function of hepatic CSCs such as Wnt/ $\beta$-catenin, Hedgehog, and Notch. Epithelial cell adhesion molecule (EpCAM) is a Wnt $/ \beta$-catenin signaling target gene. The activation of $\mathrm{Wnt} / \beta$-catenin signaling regulates EpCAM expression in $\mathrm{HCSCs}$. In CD133 HCC cells, Wnt/ $\beta$-catenin, Notchl, and smoothened (SMO)/Hedgehog signaling pathways are associated with proliferation, self-renewal, and differentiation of HCSCs.

Emerging evidences suggest that miRNAs play a key role also in the maintenance, progression, chemoresistance, and disease relapse of HCSCs $[4,5]$. For these reasons, many authors have identified in some mechanisms of "loss of stemness," regulated by miRNAs expression, novel therapeutic strategies for treatment of hepatocellular carcinoma [91].

Here, we summarized the latest findings on the therapeutic targets of miRNA in HCSCs.

4.1. Oncogenic miRNA in HCSCs. Recently it has been demonstrated that miR-10b represents a switch factor between liver normal stem cells (LNSCs) and liver cancer stem cells (LCSCs). This malignant transformation is mediated by the enhanced expression of the axis miR-10b/HOX transcript antisense RNA (HOTAIR) that induces the degradation of E-cadherin pattern in LNSCs, thus facilitating the epithelial-to-mesenchymal transition (EMT) [34]. In this way also miR-21, when silenced, induces an attenuate mRNA expression of PTEN, RECK, or PDCD4, leading to a reduction in HCSCs migration and invasion [35]. The factors regulated by miR-21 represent also a target of miR-216a and miR-217 that are able to bind specifically PTEN and SMAD7. This leads to the activation of TGF- $\beta 1 /$ PI3K/AKT signaling and to development of drug resistance to Sorafenib in HCC
[53]. It has been showed that also miR-142-3p acts as an oncogenic via CD 133, conferring HCSC-like characteristic [39].

Several studies demonstrated that miR-155 acts as oncogenic miRNA, through the interaction with the axis TGF$\beta 1 /$ TP53INP1. This causes the EMT and the acquisition of stem cell phenotype [46, 92].

4.2. miRNA Tumor Suppressors in HCSCs. It is of note that miRNAs are able to regulate several biological mechanisms. For example, miR-122 has a key role in glycolytic metabolism. It induces a reversion of malignancy phenotype of HCSCs, by regulation of glycolysis, which is more active in HCSC $\mathrm{CD}_{133^{+}}$, via inhibition of PDK4 and LDHA [37].

Several studies showed that the oncosuppressor miR-125b reduces EMT, through SMAD2/4 protein association [38]. This pathway seems to be influenced by the action of miR148a, whose expression levels are improved by Glabridin (GLA) in HepG2, Huh-7, and MHCC97H hepatic cancer cell lines. MiR-125b inhibits TGF- $\beta /$ SMAD2 axis and leads to lack of HCSC-like properties [41]. The isoform miR-148b instead acts on Neuropilin 1 (NRP1) with same effects [42]. In many studies, the interaction between some miRNAs and transcriptional factors has been described, such as Sox2, 
Oct4, Nanog, and c-myb, which play an important role in stemness maintenance $[40,44]$. MiR-145, for example, plays a critical role in HCSCs tumor suppression, by reversing the effects of OCT-4 overexpression that normally leads to gain of tumorigenicity [40]. Conversely, miR-150 interacts with $3^{\prime}$ UTR mRNA sequence of c-myb, downregulating its expression levels; in this case, it works as an oncosuppressor. Its presence is associated with a regression of HCSCs potential, probably due to a decrement of cyclin D1 and Bcl-2 levels [44].

A clinical study reported the dualistic effect of miR-150, also as an oncogene, together with miR-155 and miR-223. Their suppression is due to a decrement of $\mathrm{EpCAM}^{+}$cell population [43].

Moreover, studies performed on miR-200a demonstrated that it regulates stemness of HCSCs with a dual activity. Overexpression of this miRNA switches on the transition from LCSC to HCSC that it is observed through the expression analysis of $\mathrm{N}$-cadherin, ZEB2, and vimentin [50]. Another study on regulatory role of miR-200a showed that it acts as oncosuppressor in hepatic oval cells (HOCs), by direct interaction with $\mathrm{Wnt} / \beta$-catenin axis. Functionally attenuation of miR-200a leads to the activation of the pathway, resulting in tumorigenicity acquisition after HOCs transition [49].

$\beta$-catenin represents also the molecular target of miR214, which normally binds to the zeste homolog 2 (EZH2) factor by increasing EpCAM ${ }^{+}$cells in HCC population. The attenuation of miR-214 or EZH2 overexpression leads to same results [52].

MiR-612 regulates the EMT through a direct interaction with AKT2 [56].

Recent studies have highlighted the key role of miR-181 in HCSCs stemness maintenance through the interaction with let-7 family members. It has been demonstrated that let7/miR-181 axis is upregulated in HCSCs, and this condition leads to chemoresistance to doxorubicin or sorafenib treatment [48]. MiR-181 binds to some hepatic transcriptional regulators of differentiation as CDX2 and GATA6 or nemolike kinase (NLK). These interactions induce the pluripotent phenotype, observed through an increment of EpCAM ${ }^{+}$ alpha-fetoprotein ${ }^{+}$HCSCs [47].

Finally, recent studies reported the involvement of several miRNAs in HCSCs regulation/maintenance, through interaction with molecular target poorly studied. MiR-152, for example, shows an oncosuppressor role by targeting KIT receptor [45]; miR-205 and $\mathrm{miR}-491$, acting as oncosuppressors, interact, respectively, with PLC $\beta 1$ [51] and the GIT$1 / \mathrm{NF}-\kappa \mathrm{B}$ axis [55].

The regulatory functions of miRNAs targeted in HCSCs are summarized in Table 2.

\section{Therapeutic Targets of miRNA-Based Technology for Treatment of HCC}

In order to eradicate the HCSCs, several therapeutic approaches have been developed. Here we summarized the recent progress in HCSCs research related to HCC, trying to provide a possible perspective for treatment of chemotherapy-resistant HCC tumors.
5.1. Epigenetic Therapy. Epigenetic mechanisms, such as histone modification and DNA methylation, play several roles in cancer development and progression [93]. Several studies showed the efficacy of epigenetic agents as therapeutic approach in HCC [94]. Raggi and colleagues in experimental studies of epigenetic reprogramming showed that Zebularine, a DNA methyltransferase (DNMT) inhibitor, is able to influence CSC properties such as self-renewal and tumorigenicity in HCSCs [95]. SALL4, a transcriptor factor, is able to regulate stemness of EpCAM-positive hepatocellular carcinoma, thus representing a valuable biomarker and therapeutic target for the diagnosis and treatment of HCC with stem cell features [96].

Altogether, these data suggest that epigenetic therapy may represent a promising approach for the eradication of CSC in HCC.

5.2. Antibody Therapy. Several studies suggested that targeting CSCs with monoclonal antibody could represent a strategy to improve the outcome of cancer therapy [97]. Regarding HCC, it has been proved that monoclonal antibodies have efficacy especially against CD13, EpCAM, and CD133, to eradicate the HCSCs [27, 98, 99]. Clinical trials and preclinical experiments will be necessary to confirm the safety of antibody therapy.

5.3. Molecular-Target Therapy. Molecular-target therapy is considered a promising therapeutic approach for HCC treatment. It has been demonstrated that self-renewal of colorectal CSC function is dependent on the BMI1 [100]. Other studies demonstrated that disruption of EZH2 impairs the tumor initiating, the self-renewal, and the cancer stem cells maintenance of various type tumors, including HCC [101103]. Clinical trials would be needed to confirm if moleculartarget therapy could be applied at clinical level, for HCSCs elimination.

5.4. Therapy Targeting the HCSCs Niche. Another type of therapy developed for the eradication of HCSCs is based on targeting the HCSCs niches. Niches are identified, as specific microenvironments in which HCSCs and normal tissue stem cells are present. It has been demonstrated that sorafenib, the unique molecular-target drug approved to treat HCC at clinical level, may contribute to the eradication of HCSCs by targeting Raf/MEK/ERK pathway and receptor tyrosine kinases $[104,105]$. Clinical trials and preclinical experiments will be needed to confirm if therapy targeting the HCSCs niche could be considered innovative for HCC treatment.

5.5. miRNA in HCC Treatment. Recent evidences have suggested the potential application of miRNAs as novel strategy in cancer therapy for HCC. It has been previously described that the therapeutic application of miRNAs involves two different strategies $[106,107]$. The first one inhibits oncogenic miRNAs by miRNA antagonists [108]. The second one is represented by miRNA replacement and is based on the reintroduction of a tumor suppressor miRNA mimetic to restore a loss of function [109]. One interesting study was performed in a mouse model of HCC by using mir-26a using 
TABLE 2: The regulatory functions of miRNAs in HCSCs biology.

\begin{tabular}{|c|c|c|c|c|}
\hline miRNA & $\begin{array}{c}\text { Oncogene (OG) } \\
\text { oncosuppressor (OS) }\end{array}$ & Molecular target/pathways & Effects & Ref. \\
\hline miR-10b & OG & HOX transcript antisense RNA (HOTAIR) & $\begin{array}{c}\text { E-cadherin degradation } \\
\text { EMT }\end{array}$ & {$[34]$} \\
\hline miR-21 & OG & PTEN, RECK, and PDCD4 & Migration/invasion & {$[35]$} \\
\hline miR-122 & OS & $\begin{array}{l}\text { PDK4, LDHA, and } \\
\text { CD133 }\end{array}$ & $\begin{array}{l}\text { Glycolysis inhibition } \\
\text { increased CD } 133^{+}\end{array}$ & {$[36,37]$} \\
\hline miR-125b & OS & SMAD2, SMAD4 & EMT & {$[38]$} \\
\hline miR-142-3p & OG & CD-133 & HCSC features & [39] \\
\hline miR-145 & OS & OCT4 & Tumorigenesis enhancing & {$[40]$} \\
\hline miR-148a & OS & TGF- $\beta /$ SMAD2 & HCSC-features & {$[41]$} \\
\hline miR-148b & Os & NRP1 & HCSC-features & {$[42]$} \\
\hline $\operatorname{miR}-150$ & OG/OS & $3^{\prime} \mathrm{UTR}$ of mRNA c-myb & Cyclin D1/Bcl-2 & {$[43,44]$} \\
\hline miR-152 & OS & KIT & HCSC-features & {$[45]$} \\
\hline miR-155 & OG & TGF- $\beta 1 /$ TP53INP1 & $\begin{array}{c}\text { EMT } \\
\text { Decreased EpCAM }\end{array}$ & {$[43,46]$} \\
\hline miR-181 & OG & $\begin{array}{c}\text { let-7 } \\
\text { CDX2, GATA6, and NLK }\end{array}$ & Doxorubicin sorafenib resistance & {$[47,48]$} \\
\hline miR-200a & OG/OS & $\begin{array}{l}\text { VASH } 2 \text { in } \mathrm{ZEB} 1 / 2 \text { signaling } \\
\text { Wnt } / \beta \text {-catenin }\end{array}$ & $\begin{array}{c}\text { Transition LCSC/HCSC } \\
\text { N-cadherin, ZEB2, and vimentin }\end{array}$ & {$[49,50]$} \\
\hline miR-205 & OS & $\operatorname{PLC} \beta 1$ & HCSC-features & {$[51]$} \\
\hline $\operatorname{miR}-214$ & OS & $\mathrm{EZH} 2$ in Wnt $/ \beta$-catenin signaling & $\mathrm{EpCAM}^{+}$ & {$[52]$} \\
\hline $\operatorname{miR}-216 a$ & OG & $\begin{array}{l}\text { PTEN and SMAD7 } \\
\text { TGF- } \beta 1 / \mathrm{PI} 3 \mathrm{~K} / \mathrm{AKT}\end{array}$ & $\begin{array}{c}\text { EMT } \\
\text { Sorafenib resistance }\end{array}$ & {$[53]$} \\
\hline miR-217 & OG & $\begin{array}{l}\text { PTEN and SMAD7 } \\
\text { TGF- } \beta 1 / P I 3 K / A K T\end{array}$ & $\begin{array}{c}\text { EMT } \\
\text { Sorafenib resistance }\end{array}$ & {$[53]$} \\
\hline miR-223 & OG & - & HCSC-features & {$[43,54]$} \\
\hline miR-491 & OS & GIT-1/NF- $\kappa \mathrm{B}$ & HCSC-features & {$[55]$} \\
\hline miR-612 & OS & AKT2 & EMT & {$[56]$} \\
\hline
\end{tabular}

adenoassociated virus delivered systemically. The authors demonstrated that ectopic expression of miR-26a leads to induction of tumor-specific apoptosis and to inhibition of cancer cell proliferation [110], indicating that delivery of miRNAs may provide an important therapeutic strategy in HCC treatment. However, its value in clinical trials still needs to be confirmed. To date, very few trials investigating the role of cancer-targeted miRNA in HCC have been performed. For example, a phase I trial investigating the role of drug MRX34, a liposome-based miR-34 mimic, is currently undergoing [111]. In order to assess the role of miRNA based drugs in clinical practice and in HCC treatment, more trials are necessary [112].

\section{Conclusions}

In this review, we synthesize the latest findings on therapeutic regulation of miRNA by modulation of tumor-suppressive and oncogenic signaling pathways. Data emerging from these studies suggest that deregulation of miRNA expression controls liver cancer progression and is responsible for the chemoresistance and disease relapse of HCSCs, although the underlying mechanisms are not completely elucidated. In order to highlight the perspective of novel miRNA-based anticancer therapies for HCC treatment, more studies will be needed in the future.

\section{Competing Interests}

The authors declare that there is no conflict of interests regarding the publication of this paper.

\section{Authors' Contributions}

Sabrina Bimonte and Maddalena Leongito contributed equally to this paper.

\section{Acknowledgments}

The authors thank Massimiliano Spinelli, for kindly helping in providing informatics assistance. This work was supported by current research programs of Institute National of Tumors, IRCCS “Foundation G. Pascale,” Naples (Italy). 


\section{References}

[1] J. Bruix and M. Sherman, "Management of hepatocellular carcinoma: an update," Hepatology, vol. 53, no. 3, pp. 1020-1022, 2011.

[2] T. Reya, S. J. Morrison, M. F. Clarke, and I. L. Weissman, "Stem cells, cancer, and cancer stem cells," Nature, vol. 414, no. 6859, pp. 105-111, 2001.

[3] T. K. W. Lee, V. C. H. Cheung, and I. O. L. Ng, "Liver tumor-initiating cells as a therapeutic target for hepatocellular carcinoma," Cancer Letters, vol. 338, no. 1, pp. 101-109, 2013.

[4] K. Kitisin, M. J. Pishvaian, L. B. Johnson, and L. Mishra, "Liver stem cells and molecular signaling pathways in hepatocellular carcinoma," Gastrointestinal Cancer Research, vol. 1, no. 4, supplement 2, pp. S13-S21, 2007.

[5] S. Ma, T. K. Lee, B.-J. Zheng, K. W. Chan, and X.-Y. Guan, "CD133+ HCC cancer stem cells confer chemoresistance by preferential expression of the Akt/PKB survival pathway," Oncogene, vol. 27, no. 12, pp. 1749-1758, 2008.

[6] D. Bonnet and J. E. Dick, "Human acute myeloid leukemia is organized as a hierarchy that originates from a primitive hematopoietic cell," Nature Medicine, vol. 3, no. 7, pp. 730-737, 1997.

[7] S. K. Singh, I. D. Clarke, M. Terasaki et al., "Identification of a cancer stem cell in human brain tumors," Cancer Research, vol. 63, no. 18, pp. 5821-5828, 2003.

[8] M. Al-Hajj, M. S. Wicha, A. Benito-Hernandez, S. J. Morrison, and M. F. Clarke, "Prospective identification of tumorigenic breast cancer cells," Proceedings of the National Academy of Sciences of the United States of America, vol. 100, no. 7, pp. 39833988, 2003.

[9] C. A. O’Brien, A. Pollett, S. Gallinger, and J. E. Dick, “A human colon cancer cell capable of initiating tumour growth in immunodeficient mice," Nature, vol. 445, no. 7123, pp. 106-110, 2007.

[10] S. Zhang, C. Balch, M. W. Chan et al., "Identification and characterization of ovarian cancer-initiating cells from primary human tumors," Cancer Research, vol. 68, no. 11, pp. 4311-4320, 2008.

[11] A. B. Alvero, R. Chen, H.-H. Fu et al., "Molecular phenotyping of human ovarian cancer stem cells unravels the mechanisms for repair and chemoresistance," Cell Cycle, vol. 8, no. 1, pp. 158166,2009

[12] C. Li, D. G. Heidt, P. Dalerba et al., "Identification of pancreatic cancer stem cells," Cancer Research, vol. 67, no. 3, pp. 1030-1037, 2007.

[13] N. J. Maitland and A. T. Collins, "Prostate cancer stem cells: a new target for therapy," Journal of Clinical Oncology, vol. 26, no. 17, pp. 2862-2870, 2008.

[14] S. H. Lang, F. M. Frame, and A. T. Collins, "Prostate cancer stem cells," The Journal of Pathology, vol. 217, no. 2, pp. 299-306, 2009.

[15] M. Alamgeer, C. D. Peacock, W. Matsui, V. Ganju, and D. N. Watkins, "Cancer stem cells in lung cancer: evidence and controversies," Respirology, vol. 18, no. 5, pp. 757-764, 2013.

[16] T. Yamashita and X. W. Wang, "Cancer stem cells in the development of liver cancer," Journal of Clinical Investigation, vol. 123, no. 5, pp. 1911-1918, 2013.
[17] S. Takaishi, T. Okumura, S. Tu et al., "Identification of gastric cancer stem cells using the cell surface marker CD44," STEM CELLS, vol. 27, no. 5, pp. 1006-1020, 2009.

[18] L. Li, L. Borodyansky, and Y. Yang, "Genomic instability en route to and from cancer stem cells," Cell Cycle, vol. 8, no. 7, pp. 1000-1002, 2009.

[19] U. R. Rapp, F. Ceteci, and R. Schreck, "Oncogene-induced plasticity and cancer stem cells," Cell Cycle, vol. 7, no. 1, pp. 4551, 2008.

[20] K.-J. Wu and M.-H. Yang, "Epithelial-mesenchymal transition and cancer stemness: the Twistl-Bmil connection," Bioscience Reports, vol. 31, no. 6, pp. 449-455, 2011.

[21] L. M. Angerer and R. C. Angerer, "Regulative development of the sea urchin embryo: signalling cascades and morphogen gradients," Seminars in Cell and Developmental Biology, vol. 10, no. 3, pp. 327-334, 1999.

[22] S. A. Mani, J. Yang, M. Brooks et al., "Mesenchyme Forkhead 1 (FOXC2) plays a key role in metastasis and is associated with aggressive basal-like breast cancers," Proceedings of the National Academy of Sciences of the United States of America, vol. 104, no. 24, pp. 10069-10074, 2007.

[23] S. Ma, K.-W. Chan, L. Hu et al., "Identification and characterization of tumorigenic liver cancer stem/progenitor cells," Gastroenterology, vol. 132, no. 7, pp. 2542-2556, 2007.

[24] L. S. Piao, W. Hur, T.-K. Kim et al., "CD133 + liver cancer stem cells modulate radioresistance in human hepatocellular carcinoma," Cancer Letters, vol. 315, no. 2, pp. 129-137, 2012.

[25] Z. F. Yang, D. W. Ho, M. N. Ng et al., "Significance of CD90 cancer stem cells in human liver cancer," Cancer Cell, vol. 13, no. 2, pp. 153-166, 2008.

[26] Z. Zhu, X. Hao, M. Yan et al., "Cancer stem/progenitor cells are highly enriched in CD133+CD44+ population in hepatocellular carcinoma," International Journal of Cancer, vol. 126, no. 9, pp. 2067-2078, 2010.

[27] N. Haraguchi, H. Ishii, K. Mimori et al., "CD13 is a therapeutic target in human liver cancer stem cells," The Journal of Clinical Investigation, vol. 120, no. 9, pp. 3326-3339, 2010.

[28] T. K. Lee, A. Castilho, V. C. Cheung, K. H. Tang, S. Ma, and I. O. Ng, "CD24 ${ }^{+}$liver tumor-initiating cells drive self-renewal and tumor initiation through STAT3-mediated NANOG regulation," Cell Stem Cell, vol. 9, no. 1, pp. 50-63, 2011.

[29] W. Yang, H.-X. Yan, L. Chen et al., "Wnt/ $\beta$-catenin signaling contributes to activation of normal and tumorigenic liver progenitor cells," Cancer Research, vol. 68, no. 11, pp. 4287-4295, 2008.

[30] X. Xu, R.-F. Liu, X. Zhang et al., "DLK1 as a potential target against cancer stem/progenitor cells of hepatocellular carcinoma," Molecular Cancer Therapeutics, vol. 11, no. 3, pp. 629638, 2012.

[31] T. Yamashita, M. Forgues, W. Wang et al., "EpCAM and $\alpha$ fetoprotein expression defines novel prognostic subtypes of hepatocellular carcinoma," Cancer Research, vol. 68, no. 5, pp. 1451-1461, 2008.

[32] S. T. Cheung, P. F. Y. Cheung, C. K. C. Cheng, N. C. L. Wong, and S. T. Fan, "Granulin-epithelin precursor and ATPdependent binding cassette $(\mathrm{ABC}) \mathrm{B} 5$ regulate liver cancer cell chemoresistance," Gastroenterology, vol. 140, no. 1, pp. 344-355, 2011. 
[33] T. Chiba, K. Kita, Y.-W. Zheng et al., "Side population purified from hepatocellular carcinoma cells harbors cancer stem celllike properties," Hepatology, vol. 44, no. 1, pp. 240-251, 2006.

[34] P. Ye, T. Wang, W.-H. Liu, X.-C. Li, L.-J. Tang, and F.-Z. Tian, "Enhancing HOTAIR/MIR-10b drives normal liver stem cells toward a tendency to malignant transformation through inducing epithelial- to-mesenchymal transition," Rejuvenation Research, vol. 18, no. 4, pp. 332-340, 2015.

[35] L. Zhou, Z.-X. Yang, W.-J. Song et al., "MicroRNA-21 regulates the migration and invasion of a stem-like population in hepatocellular carcinoma," International Journal of Oncology, vol. 43, no. 2, pp. 661-669, 2013.

[36] C. Coulouarn, V. M. Factor, J. B. Andersen, M. E. Durkin, and S. S. Thorgeirsson, "Loss of miR-122 expression in liver cancer correlates with suppression of the hepatic phenotype and gain of metastatic properties," Oncogene, vol. 28, no. 40, pp. 3526-3536, 2009.

[37] K. Song, H. Kwon, C. Han et al., "Active glycolytic metabolism in CD133(+) hepatocellular cancer stem cells: regulation by MIR122," Oncotarget, vol. 6, no. 38, pp. 40822-40835, 2015.

[38] J.-N. Zhou, Q. Zeng, H.-Y. Wang et al., "MicroRNA-125b attenuates epithelial-mesenchymal transitions and targets stemlike liver cancer cells through small mothers against decapentaplegic 2 and 4," Hepatology, vol. 62, no. 3, pp. 801-815, 2015.

[39] S. Chai, M. Tong, K. Y. Ng et al., "Regulatory role of miR-142$3 p$ on the functional hepatic cancer stem cell marker CD133," Oncotarget, vol. 5, no. 14, pp. 5725-5735, 2014.

[40] Y. Jia, H. Liu, Q. Zhuang et al., “Tumorigenicity of cancer stem-like cells derived from hepatocarcinoma is regulated by microRNA-145," Oncology Reports, vol. 27, no. 6, pp. 1865-1872, 2012.

[41] F. Jiang, J. Mu, X. Wang et al., "The repressive effect of miR-148a on TGF beta-SMADs signal pathway is involved in the glabridin-induced inhibition of the cancer stem cells-like properties in hepatocellular carcinoma cells," PLoS ONE, vol. 9, no. 5, Article ID e96698, 2014.

[42] Q. Liu, Y. Xu, S. Wei et al., "miRNA-148b suppresses hepatic cancer stem cell by targeting neuropilin-1," Bioscience Reports, vol. 35, no. 4, Article ID e00229, 2015.

[43] J. Ji, X. Zheng, M. Forgues et al., "Identification of microRNAs specific for epithelial cell adhesion molecule-positive tumor cells in hepatocellular carcinoma," Hepatology, vol. 62, no. 3, pp. 829-840, 2015.

[44] J. Zhang, N. Luo, Y. Luo, Z. Peng, T. Zhang, and S. Li, "MicroRNA-150 inhibits human CD133-positive liver cancer stem cells through negative regulation of the transcription factor c-Myb," International Journal of Oncology, vol. 40, no. 3, pp. 747-756, 2012.

[45] H. Huang, M. Hu, P. Li, C. Lu, and M. Li, "Mir-152 inhibits cell proliferation and colony formation of $\mathrm{CD} 33^{+}$liver cancer stem cells by targeting KIT,' Tumor Biology, vol. 36, no. 2, pp. 921-928, 2015.

[46] F. Liu, X. Kong, L. Lv, and J. Gao, “TGF- $\beta 1$ acts through miR-155 to down-regulate TP53INP1 in promoting epithelialmesenchymal transition and cancer stem cell phenotypes," Cancer Letters, vol. 359, no. 2, pp. 288-298, 2015.

[47] J. Ji, T. Yamashita, A. Budhu et al., "Identification of microRNA181 by genome-wide screening as a critical player in EpCAMpositive hepatic cancer stem cells," Hepatology, vol. 50, no. 2, pp. $472-480,2009$.
[48] F. Meng, S. S. Glaser, H. Francis et al., "Functional analysis of microRNAs in human hepatocellular cancer stem cells," Journal of Cellular and Molecular Medicine, vol. 16, no. 1, pp. 160-173, 2012.

[49] J. Liu, B. Ruan, N. You et al., "Downregulation of miR-200a induces EMT phenotypes and CSC-like signatures through targeting the $\beta$-catenin pathway in hepatic oval cells," PLoS ONE, vol. 8, no. 11, Article ID e79409, 2013.

[50] J. Wang, X. Yang, B. Ruan et al., "Overexpression of miR-200a suppresses epithelial-mesenchymal transition of liver cancer stem cells," Tumor Biology, vol. 36, no. 4, pp. 2447-2456, 2015.

[51] J. Zhao, G. Xu, Y. Wang, D. Qian, Y. Wang, and Y. Li, “Downregulation of miR-205 promotes stemness of hepatocellular carcinoma cells by targeting PLCbetal and increasing CD24 expression," Neoplasma, vol. 62, no. 4, pp. 567-573, 2015.

[52] H. Xia, L. L. P. J. Ooi, and K. M. Hui, "MiR-214 targets $\beta$-catenin pathway to suppress invasion, stem-like traits and recurrence of human hepatocellular carcinoma," PLoS ONE, vol. 7, no. 9, Article ID e44206, 2012.

[53] H. Xia, L. L. P. J. Ooi, and K. M. Hui, "MicroRNA-216a/217induced epithelial-mesenchymal transition targets PTEN and SMAD7 to promote drug resistance and recurrence of liver cancer," Hepatology, vol. 58, no. 2, pp. 629-641, 2013.

[54] Q. W.-L. Wong, R. W.-M. Lung, P. T.-Y. Law et al., "MicroRNA223 is commonly repressed in hepatocellular carcinoma and potentiates expression of stathmin1," Gastroenterology, vol. 135, no. 1, pp. 257-269, 2008.

[55] X. Yang, J. Ye, H. Yan et al., "MiR-491 attenuates cancer stem cells-like properties of hepatocellular carcinoma by inhibition of GIT-1/NF- $\kappa$ B-mediated EMT," Tumor Biology, 2015.

[56] J. Tang, Z.-H. Tao, D. Wen et al., "MiR-612 suppresses the stemness of liver cancer via Wnt/ $\beta$-catenin signaling," Biochemical and Biophysical Research Communications, vol. 447, no. 1, pp. 210-215, 2014.

[57] E. Pardali, M.-J. Goumans, and P. ten Dijke, "Signaling by members of the TGF- $\beta$ family in vascular morphogenesis and disease," Trends in Cell Biology, vol. 20, no. 9, pp. 556-567, 2010.

[58] J. Massague, "TGFbeta signalling in context," Nature Reviews Molecular Cell Biology, vol. 13, no. 10, pp. 616-630, 2012.

[59] H. Ikushima and K. Miyazono, "TGFB 2 signalling: a complex web in cancer progression," Nature Reviews Cancer, vol. 10, no. 6, pp. 415-424, 2010.

[60] Y. Tang, K. Kitisin, W. Jogunoori et al., "Progenitor/stem cells give rise to liver cancer due to aberrant TGF- $\beta$ and IL-6 signaling," Proceedings of the National Academy of Sciences of the United States of America, vol. 105, no. 7, pp. 2445-2450, 2008.

[61] M. J. Macias, P. Martin-Malpartida, and J. Massague, "Structural determinants of Smad function in TGF-beta signaling," Trends in Biochemical Sciences, vol. 40, no. 6, pp. 296-308, 2015.

[62] J. Massagué, “TGF- $\beta$ signal transduction,” Annual Review of Biochemistry, vol. 67, pp. 753-791, 1998.

[63] L. Zhang, F. Zhou, and P. ten Dijke, "Signaling interplay between transforming growth factor- $\beta$ receptor and PI3K/AKT pathways in cancer," Trends in Biochemical Sciences, vol. 38, no. 12 , pp. 612-620, 2013.

[64] Y. E. Zhang, "Non-Smad pathways in TGF- $\beta$ signaling," Cell Research, vol. 19, no. 1, pp. 128-139, 2009. 
[65] L. Luo, N. Li, N. Lv, and D. Huang, "SMAD7: a timer of tumor progression targeting TGF- $\beta$ signaling," Tumor Biology, vol. 35, no. 9, pp. 8379-8385, 2014.

[66] H. T. Ha Thi, H.-Y. Kim, S.-W. Choi, J.-M. Kang, S.-J. Kim, and S. Hong, "Smad7 modulates epidermal growth factor receptor turnover through sequestration of c-Cbl," Molecular and Cellular Biology, vol. 35, no. 16, pp. 2841-2850, 2015.

[67] F. Yuan, W. Zhou, C. Zou et al., "Expression of Oct4 in HCC and modulation to wnt/ $\beta$-catenin and TGF- $\beta$ signal pathways," Molecular and Cellular Biochemistry, vol. 343, no. 1-2, pp. 155$162,2010$.

[68] M. Branda and J. R. Wands, "Signal transduction cascades and hepatitis B and C related hepatocellular carcinoma," Hepatology, vol. 43, no. 5, pp. 891-902, 2006.

[69] C. Y. Logan and R. Nusse, "The Wnt signaling pathway in development and disease," Annual Review of Cell and Developmental Biology, vol. 20, pp. 781-810, 2004.

[70] T. Reya and H. Clevers, "Wnt signalling in stem cells and cancer," Nature, vol. 434, no. 7035, pp. 843-850, 2005.

[71] V. J. M. Wielenga, R. Smits, V. Korinek et al., "Expression of CD44 in Apc and Tcf mutant mice implies regulation by the WNT pathway," American Journal of Pathology, vol. 154, no. 2, pp. 515-523, 1999.

[72] O. Tetsu and F. McCormick, " $\beta$-Catenin regulates expression of cyclin D1 in colon carcinoma cells," Nature, vol. 398, no. 6726, pp. 422-426, 1999.

[73] T.-C. He, A. B. Sparks, C. Rago et al., "Identification of c-MYC as a target of the APC pathway," Science, vol. 281, no. 5382, pp. 1509-1512, 1998.

[74] D. Feng, N. Wang, J. Hu, and W. Li, "Surface markers of hepatocellular cancer stem cells and their clinical potential," Neoplasma, vol. 61, no. 5, pp. 505-513, 2014.

[75] T. Yamashita, J. Ji, A. Budhu et al., "EpCAM-positive hepatocellular carcinoma cells are tumor-initiating cells with stem/progenitor cell features," Gastroenterology, vol. 136, no. 3, pp. 1012-1024, 2009.

[76] D. Fong, A. Seeber, L. Terracciano et al., "Expression of $\operatorname{EpCAM(MF)~and~EpCAM(MT)~variants~in~human~carcino-~}$ mas," Journal of Clinical Pathology, vol. 67, no. 5, pp. 408-414, 2014.

[77] D. Maetzel, S. Denzel, B. Mack et al., "Nuclear signalling by tumour-associated antigen EpCAM," Nature Cell Biology, vol. 11, no. 2, pp. 162-171, 2009.

[78] T.-Y. Lu, R.-M. Lu, M.-Y. Liao et al., "Epithelial cell adhesion molecule regulation is associated with the maintenance of the undifferentiated phenotype of human embryonic stem cells," The Journal of Biological Chemistry, vol. 285, no. 12, pp. 8719$8732,2010$.

[79] T. Yamashita, A. Budhu, M. Forgues, and W. W. Xin, "Activation of hepatic stem cell marker EpCAM by Wnt- $\beta$-catenin signaling in hepatocellular carcinoma," Cancer Research, vol. 67, no. 22, pp. 10831-10839, 2007.

[80] L. Zhou, Y. Huang, J. Li, and Z. Wang, “The mTOR pathway is associated with the poor prognosis of human hepatocellular carcinoma," Medical Oncology, vol. 27, no. 2, pp. 255-261, 2010.

[81] S. Watanabe, Y. Horie, E. Kataoka et al., "Non-alcoholic steatohepatitis and hepatocellular carcinoma: lessons from hepatocyte-specific phosphatase and tensin homolog (PTEN)deficient mice," Journal of Gastroenterology and Hepatology, vol. 22, supplement 1, pp. S96-S100, 2007.

[82] L. Wang, W.-L. Wang, Y. Zhang, S.-P. Guo, J. Zhang, and Q.-L. $\mathrm{Li}$, "Epigenetic and genetic alterations of PTEN in hepatocellular carcinoma," Hepatology Research, vol. 37, no. 5, pp. 389-396, 2007.

[83] A. P. McMahon, P. W. Ingham, and C. J. Tabin, "1 Developmental roles and clinical significance of Hedgehog signaling," Current Topics in Developmental Biology, vol. 53, pp. 1-114, 2003.

[84] P. W. Ingham and A. P. McMahon, "Hedgehog signaling in animal development: paradigms and principles," Genes and Development, vol. 15, no. 23, pp. 3059-3087, 2001.

[85] K. Koebernick and T. Pieler, "Gli-type zinc finger proteins as bipotential transducers of Hedgehog signaling," Differentiation, vol. 70, no. 2-3, pp. 69-76, 2002.

[86] J. K. Sicklick, Y.-X. Li, A. Jayaraman et al., "Dysregulation of the Hedgehog pathway in human hepatocarcinogenesis," Carcinogenesis, vol. 27, no. 4, pp. 748-757, 2006.

[87] S. Huang, J. He, X. Zhang et al., "Activation of the hedgehog pathway in human hepatocellular carcinomas," Carcinogenesis, vol. 27, no. 7, pp. 1334-1340, 2006.

[88] P. Pineau, S. Volinia, K. McJunkin et al., "miR-221 overexpression contributes to liver tumorigenesis," Proceedings of the National Academy of Sciences of the United States of America, vol. 107, no. 1, pp. 264-269, 2010

[89] S. Ma, K. H. Tang, Y. P. Chan et al., "MiR-130b promotes CD133' liver tumor-initiating cell growth and self-renewal via tumor protein 53-induced nuclear protein 1," Cell Stem Cell, vol. 7, no. 6, pp. 694-707, 2010.

[90] Q. W.-L. Wong, A. K.-K. Ching, A. W.-H. Chan et al., "MiR222 overexpression confers cell migratory advantages in hepatocellular carcinoma through enhancing AKT signaling," Clinical Cancer Research, vol. 16, no. 3, pp. 867-875, 2010.

[91] T. Chiba, A. Iwama, and O. Yokosuka, "Cancer stem cells in hepatocellular carcinoma: therapeutic implications based on stem cell biology," Hepatology Research, vol. 46, no. 1, pp. 50$57,2016$.

[92] F. Liu, X. Kong, L. Lv, and J. Gao, "MiR-155 targets TP53INP1 to regulate liver cancer stem cell acquisition and self-renewal," FEBS Letters, vol. 589, no. 4, pp. 500-506, 2015.

[93] M. Esteller, "Epigenetics in cancer," The New England Journal of Medicine, vol. 358, no. 11, pp. 1148-1159, 2008.

[94] J. U. Marquardt and S. S. Thorgeirsson, "SnapShot: hepatocellular carcinoma," Cancer Cell, vol. 25, no. 4, p. 550.el, 2014.

[95] C. Raggi, V. M. Factor, D. Seo et al., "Epigenetic reprogramming modulates malignant properties of human liver cancer," Нераtology, vol. 59, no. 6, pp. 2251-2262, 2014.

[96] S. S. Zeng, T. Yamashita, M. Kondo et al., "The transcription factor SALL4 regulates stemness of EpCAM-positive hepatocellular carcinoma," Journal of Hepatology, vol. 60, no. 1, pp. 127134, 2014.

[97] M. P. Deonarain, C. A. Kousparou, and A. A. Epenetos, "Antibodies targeting cancer stem cells: a new paradigm in immunotherapy?" mAbs, vol. 1, no. 1, pp. 12-25, 2009.

[98] K. Ogawa, S. Tanaka, S. Matsumura et al., "EpCAM-targeted therapy for human hepatocellular carcinoma," Annals of Surgical Oncology, vol. 21, no. 4, pp. 1314-1322, 2014. 
[99] L. M. Smith, A. Nesterova, M. C. Ryan et al., "CD133/prominin1 is a potential therapeutic target for antibody-drug conjugates in hepatocellular and gastric cancers," British Journal of Cancer, vol. 99, no. 1, pp. 100-109, 2008.

[100] A. Kreso, P. Van Galen, N. M. Pedley et al., "Self-renewal as a therapeutic target in human colorectal cancer," Nature Medicine, vol. 20, no. 1, pp. 29-36, 2014.

[101] M.-L. Suvà, N. Riggi, M. Janiszewska et al., "EZH2 is essential for glioblastoma cancer stem cell maintenance," Cancer Research, vol. 69, no. 24, pp. 9211-9218, 2009.

[102] B. Xu, D. M. On, A. Ma et al., "Selective inhibition of EZH2 and EZH1 enzymatic activity by a small molecule suppresses MLLrearranged leukemia," Blood, vol. 125, no. 2, pp. 346-357, 2015.

[103] M. T. McCabe, H. M. Ott, G. Ganji et al., "EZH2 inhibition as a therapeutic strategy for lymphoma with EZH2-activating mutations," Nature, vol. 491, no. 7427, pp. 108-112, 2012.

[104] R. J. Gilbertson and J. N. Rich, "Making a tumour's bed: glioblastoma stem cells and the vascular niche," Nature Reviews Cancer, vol. 7, no. 10, pp. 733-736, 2007.

[105] S. M. Wilhelm, C. Carter, L. Tang et al., "BAY 43-9006 exhibits broad spectrum oral antitumor activity and targets the RAF/MEK/ERK pathway and receptor tyrosine kinases involved in tumor progression and angiogenesis," Cancer Research, vol. 64, no. 19, pp. 7099-7109, 2004.

[106] M. D’Anzeo, L. Faloppi, M. Scartozzi et al., “The role of MicroRNAs in hepatocellular carcinoma: frommolecular biology to treatment," Molecules, vol. 19, no. 5, pp. 6393-6406, 2014.

[107] M. Lindow and S. Kauppinen, "Discovering the first microRNAtargeted drug," The Journal of Cell Biology, vol. 199, no. 3, pp. 407-412, 2012.

[108] J. Krützfeldt, S. Kuwajima, R. Braich et al., "Specificity, duplex degradation and subcellular localization of antagomirs," Nucleic Acids Research, vol. 35, no. 9, pp. 2885-2892, 2007.

[109] A. G. Bader, D. Brown, and M. Winkler, "The promise of microRNA replacement therapy," Cancer Research, vol. 70, no. 18, pp. 7027-7030, 2010

[110] J. Kota, R. R. Chivukula, K. A. O'Donnell et al., “Therapeutic microRNA delivery suppresses tumourigenesis in a murine liver cancer model," Cell, vol. 137, no. 6, pp. 1005-1017, 2009.

[111] H. Ling, M. Fabbri, and G. A. Calin, "MicroRNAs and other non-coding RNAs as targets for anticancer drug development," Nature Reviews. Drug Discovery, vol. 12, no. 11, pp. 847-865, 2013.

[112] C. Shibata, M. Otsuka, T. Kishikawa et al., "Current status of miRNA-targeting therapeutics and preclinical studies against gastroenterological carcinoma," Molecular and Cellular Therapies, vol. 1, article 5, 2013. 

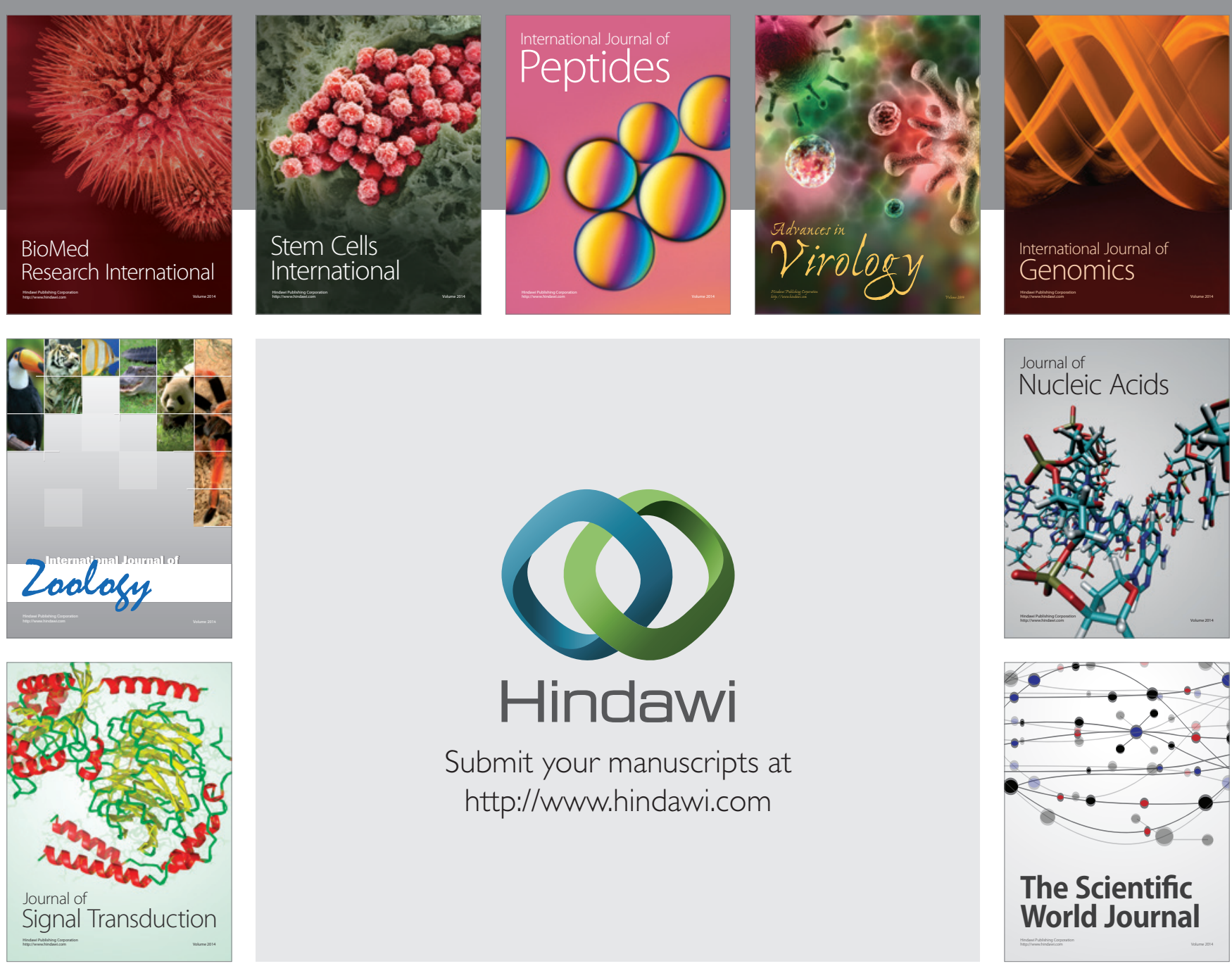

Submit your manuscripts at

http://www.hindawi.com
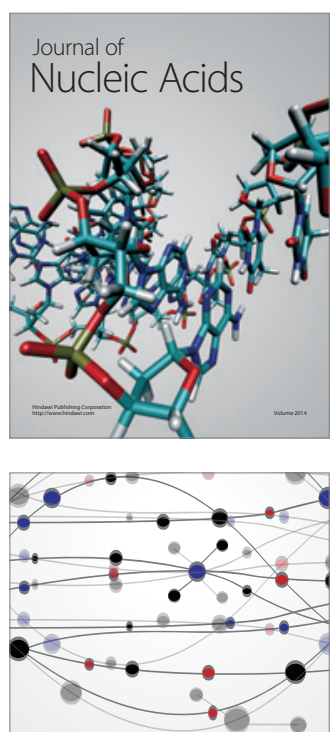

The Scientific World Journal
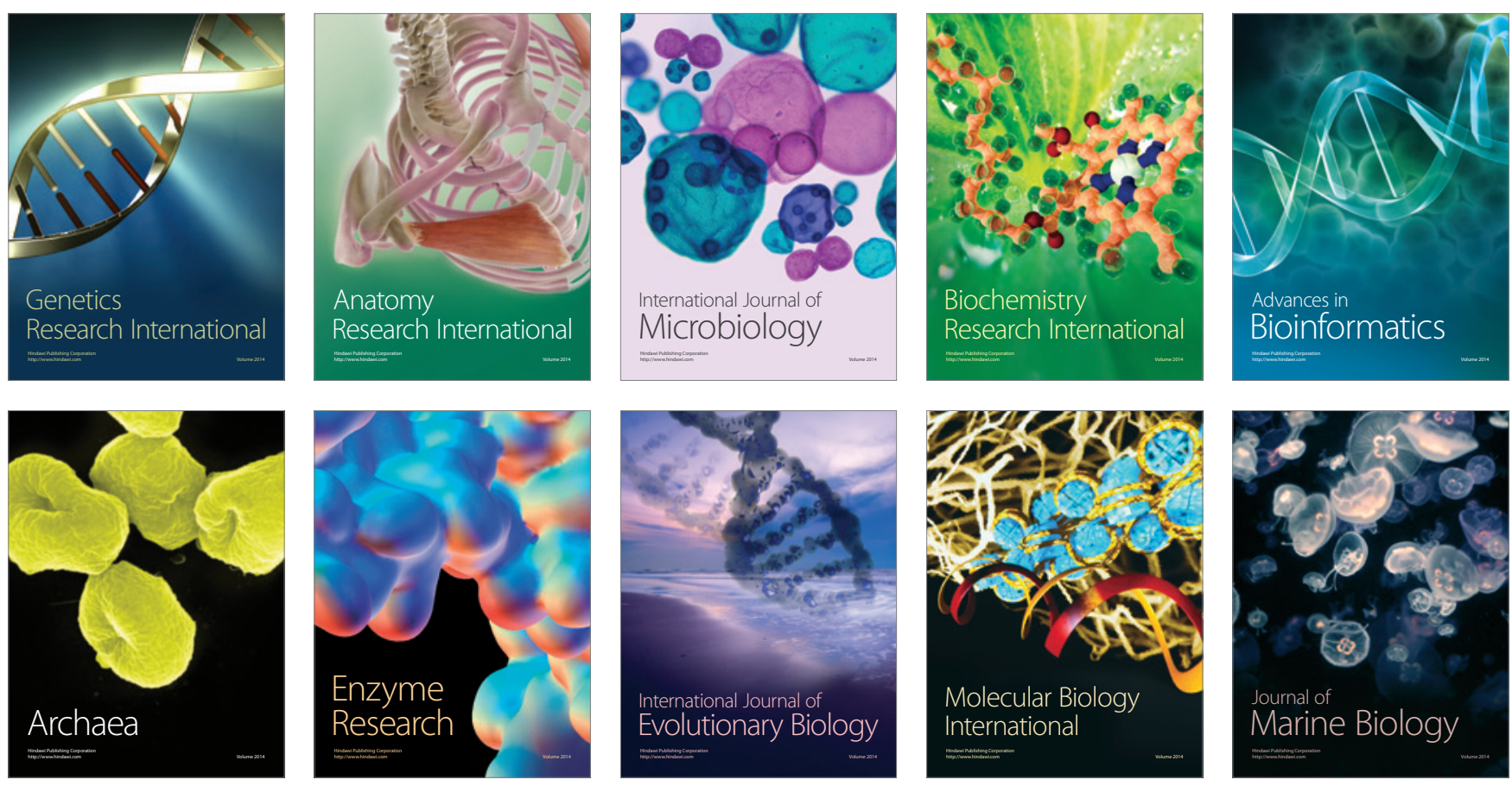